\title{
Harm Issue Editorial
}

\section{Ben Bramble ${ }^{1}$}

Accepted: 6 November 2019/Published online: 16 November 2019

(C) Springer Nature B.V. 2019

The papers on harm published in this issue of ETMP derive from the contributions to a workshop on harm ("Harm: The Concept and Its Relevance") held at Uppsala Universitet in August 2016. As the title of the workshop suggests, the papers consider either (1) how harm should be understood or (2) harm's normative relevance or significance. A number of them consider both these things, indeed arguing from accounts of the latter to the former.

The first two papers directly concern the viability of the counterfactual comparative account (CCA) of harm. According to CCA, a given event harms someone just in case it makes her worse off than she would have been had it not occurred.

Erik Carlson, in "More Problems for the Counterfactual Comparative Account of Harm and Benefit", argues that CCA faces a big problem - namely, that it is incompatible with the prudential and moral relevance of harms and benefits. Carlson raises a number of possible responses to this problem, but ultimately concludes that they do not succeed.

Neil Feit, in "Harming by Failing to Benefit", considers the problem of omission for CCA. This problem, in short, is that CCA seems to imply, implausibly, that failing to benefit someone necessarily harms that person. Feit responds that the relevant cases of failing to benefit are in fact cases of harming. They are cases of preventive harm. He tries to show that the idea that no harm occurs in these cases is not so counterintuitive as it might at first seem. Importantly, he argues that the relevant implication of CCA here is consistent with a variety of plausible views about the moral significance of harm.

The next two papers concern one of the central questions of population ethics, that of whether it can benefit or harm someone to bring them into existence.

Jens Johansson, in "The Subject of Harm in Non-Identity Cases", considers two possible responses to the non-identity problem - i.e., the worry that certain actions seem morally wrong even though, by affecting people's future identities, they seem not to harm anyone. The first response Johansson considers is that the actions in non-identity cases in fact harm the actual person whose identity has been affected. The second is that these actions make the relevant counterfactual person worse off. Johansson concludes by suggesting that we should seriously consider the following alternative: that it is in some sense a compound of the actual and the counterfactual person who is made worse off by the action.

Ben Bramble

bbramble@princeton.edu 
Per Algander, in "The Harmlessness of Existence", argues that the only way existence could benefit or harm a person is if benefiting and harming is understood in terms of actual, extrinsic value. But understanding benefiting and harming in these terms, he says, deprives them of their normative relevance. A person guided by promoting actual extrinsic value will be faced with situations where they cannot rationally decide what to do, either prudentially or morally. For this reason, Algander concludes, existence cannot benefit or harm somebody.

Algander, Carlson, and Feit all appeal, in different ways, to the normative relevance of harm in defending various accounts of the nature of harm. In a similar fashion, the final three papers all explicitly concern the relationship between the nature of harm and its normative significance.

Matthew Hanser, in "Understanding Harm and its Moral Significance", considers how we must understand harm if we are to vindicate the popular deontological idea that preventing harm takes a certain priority over improving the condition of badly-off people who have not suffered harm.

Katharina Berndt Rasmussen, in "Harm and Discrimination", argues that we can account for the wrongness of discrimination only by appeal to a comparative, counterfactual, hybrid (partly welfarist, partly non-welfarist) account of the concept of harm, one which relies on counterfactual comparisons of ways of being treated (rather than well-being levels).

Finally, Molly Gardner, in "When Good Things Happen to Harmed People", tackles the question of why it is okay for a lifeguard to break a swimmer's arm in order to save her life, but not for a Nazi to imprison a man who later grows wiser as a result of the experience. She rejects solutions having to do with consent, expected utility, and the types of harms and benefits involved. She argues instead for a causal solution. At the heart of her solution is the following principle: A harmful action that causes greater benefits can sometimes be justified by those benefits, but a harmful action that does not cause greater benefits cannot be justified by any subsequent benefits that the action, itself, does not cause. 